\title{
Optimization of Component Characteristics in EMI Filter Using CST MWS Yao Tong ${ }^{1}$ \\ ${ }^{1}$ School of Electric Power Engineering, North China Electric Power University, Baoding 071000, China \\ 1'tzsshj@163.com
}

Keywords: EMI filter; Component parameters; CST MWS; 3-D electromagnetic modeling

\begin{abstract}
This paper is devoted to the design of electromagnetic interference (EMI) filter circuit. In particular, the component parameters are carefully considered and optimized in assistance of 3-D electromagnetic software CST MWS. What distinguishes this paper from others is that an overall model of the filter instead of isolated components is constructed.
\end{abstract}

\section{Introduction}

To meet electromagnetic compatibility (EMC) requirements, EMI filter is of great significance. However, the research of the component characteristics has been temporarily out of the focus, which deserves equivalent concern. To fill the void, this paper presented here aims to the optimize the filter design in terms of component parameters using CST MWS. This paper firstly introduces a preliminary filter circuit to be improved. X capacitor, Y capacitor and common-mode(CM) inductor are modeled in CST MWS. The components are modified and the filter is constructed which proves to have good filtering performance.

\section{Preliminary EMI filter circuit}

In search of the most suitable parameters, it would be more convenient to start from the filter prevailing in the market. A typical filter circuit is proposed as the preliminary design(Fig.1) .

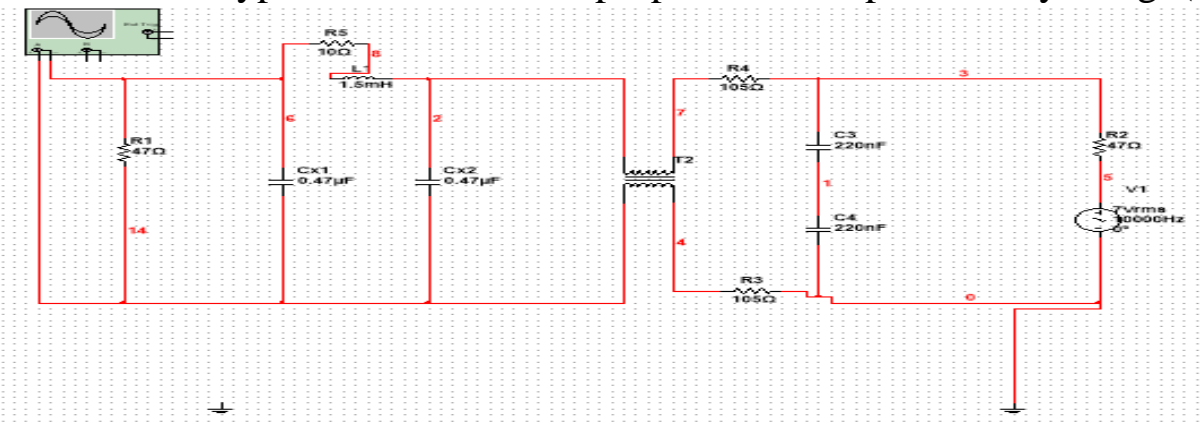

Fig.1 The preliminary filter design with typical component parameters.

\section{Capacitor Modeling}

\section{Capacitor Modeling.}

The actual capacitor(Fig.2) is manufactured with conductive film layer inside. For convenience,the model is simplified to be filled with internal normal conductor. Two thin dielectrics are attached to the normal conductor,covered with identical pieces of perfect conductor outside,from which the wires are led with length $5 \mathrm{~mm}$ each. Measurement is carried out precisely to simulate the actual capacitor. The distance between the plates $\mathrm{d}=0.014 \mathrm{~m}$, the plate area $\mathrm{A}=0.5 e^{-4}$ $m^{2}$. According to the formula: $C=\frac{\xi_{r} \cdot S}{4 \pi k d}$, Relative permittivity $\varepsilon_{\mathrm{r}}=1.04 e^{7}$. Thus the capacitor is modeled( Fig.3). 


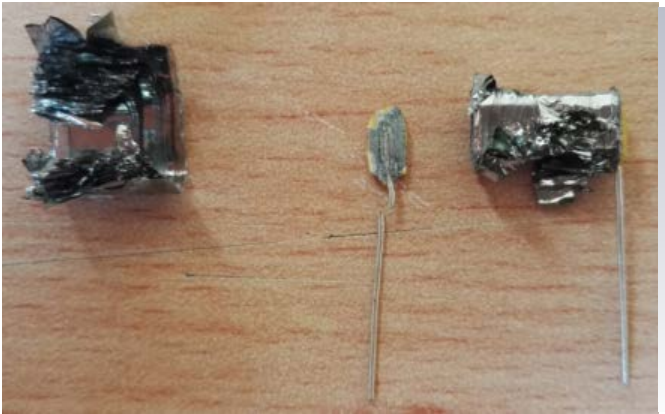

Fig.2 X capacitor prototype and the inner structure

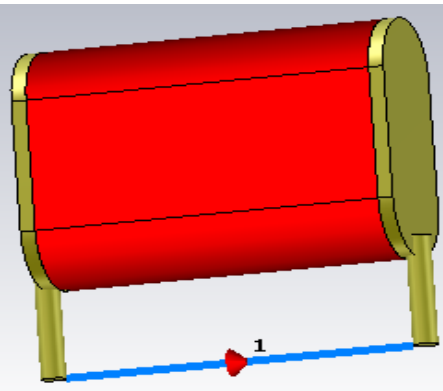

Fig.3 X capacitor model

\section{Analysis and Result of X Capacitor.}

The background substance is selected as air and is extended $20 \mathrm{~mm}$ outward from the model in three directions. The external boundary is set as short-circuit boundary $E_{t}=0$. Default mesh dissection is adopted. Z-parameters is depicted in Fig.4,which contains oscillation and energy divergence. Post-process the data by adopting the default AR filter setting and the result is illuminated in Fig.5.
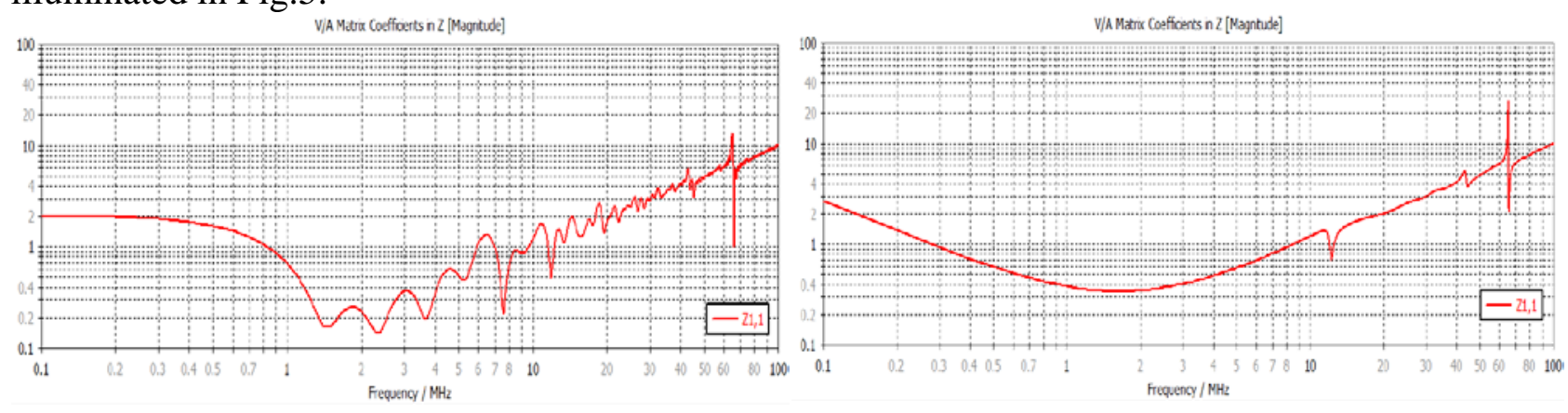

Fig.4 Z-parameters of X capacitor

Fig.5 Z-parameter after AR filter of X capacitor

3 marks are attached to the curve as below(Fig.6 ). The impedance at $0.2 \mathrm{MHz}$ is $1.37 \mathrm{Ohm}$,thus the capacitance is $0.58 \mathrm{uF}$. The impedance is $3 \mathrm{Ohm}$ at $30 \mathrm{MHZ}$,so the inductance value is $15.9 \mathrm{nH}$. As the dielectric loss factor of the second mark is 0.001 ,the impedance is $0.343 \mathrm{Ohm}$ at $1.66 \mathrm{MHz}$. The RLC values in series connection are determined.
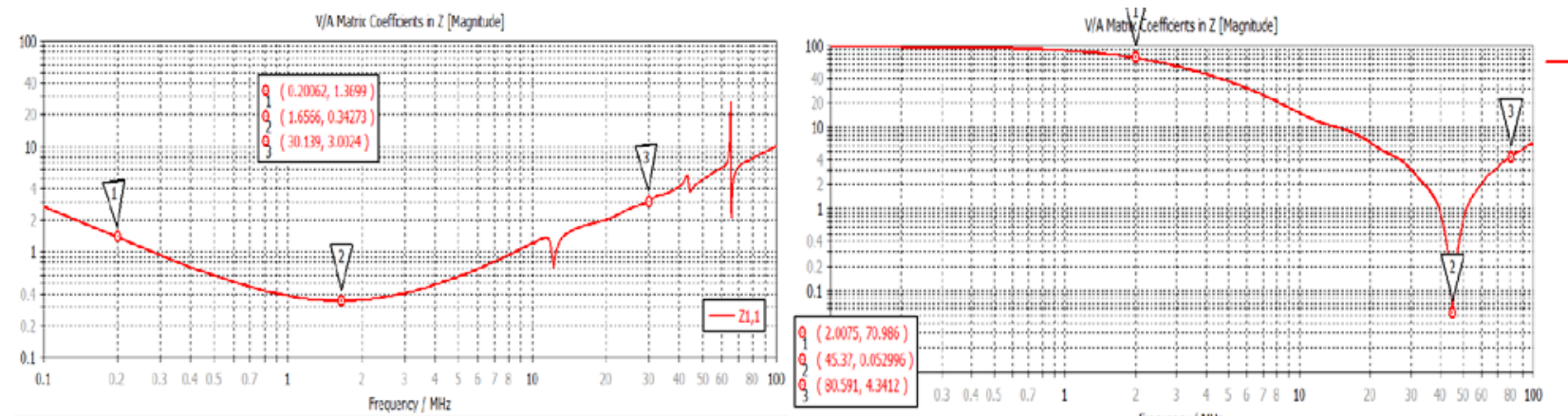

Fig.6 Z-parameter after AR filter of X capacitor attached with marks

Fig.7 Z-parameters of Y capacitor

\section{Y capacitor Modeling and Analysis.}

Similarly, Y capacitor is modeled.The distance between the two plates $\mathrm{d}=0.005 \mathrm{~m}$, the plate area $\mathrm{A}=0.5 e^{-6} \mathrm{~m}^{2}$,relative permittivity $\varepsilon_{\mathrm{r}}=1.13 e^{5}$. Attach 3marks to the Z-parameter curve and we get Fig.7. The impedance at $2 \mathrm{MHz}$ is $71.0 \mathrm{Ohm}$,thus the capacitance is $0.001 \mathrm{uF}$. The impedance is 4.3 Ohm at 80MHZ,so the inductance value is $8.55 \mathrm{nH}$. As the dielectric loss factor of the second mark is 0.001 ,the impedance is $0.05 \mathrm{Ohm}$ at $45.37 \mathrm{MHz}$. The RLC values in series connection are determined. 


\section{Common-mode inductor modeling}

\section{Inductor Modeling.}

As is shown in Fig.8,the common-mode inductor is modeled.The dimensions and the material are set the same as the prototype.Two identical coils with 5 turns each are winded around the core in reverse symmetrically.

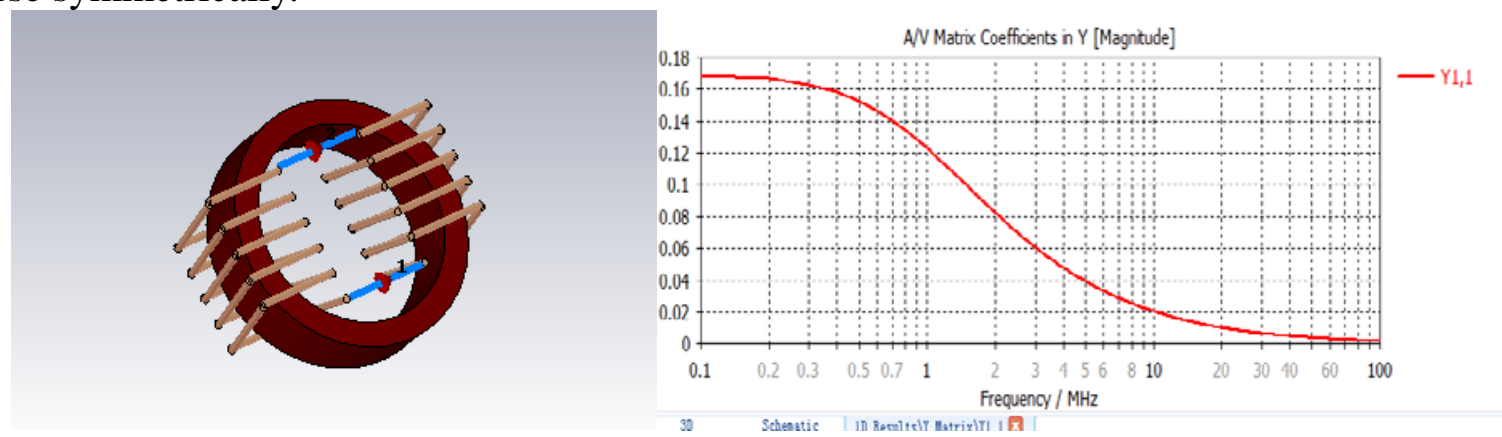

Fig.8 3-D model of Inductor

Fig.9 Y versus frequency in condition of differential-mode interference

\section{Differential-mode Interference.}

Two ports are defined at the ends of both coils and DM interference analysis is conducted. Z1-1 does not represent the impedance curve due to the existence of the ports.Thus Z-parameter(the reciprocal of Y1-1) is calculated by EXCEL after Y1-1 is obtained and exported(Fig.10)

DM Analysis

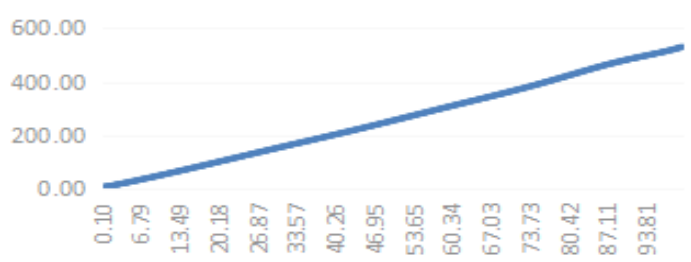

Impedence Curve

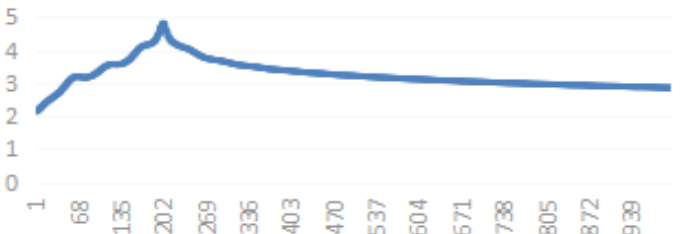

Fig. 10 1/Y1-1 versus frequency in condition of differential-mode interference Fig.11 Impedance Curve of CM analysis

\section{Common-mode Interference.}

$\mathrm{CM}$ interference analysis of the CM inductor is conducted. The PCB material is normal dielectric with dielectric constant is 4.5.The bottom layer of PCB is perfect conductor serving as ground.1/Y1-1 is obtained by EXCEL(Fig.11).

\section{Modeling of circuit}

\section{DM modeling \& Analysis.}

To reduce the effect of mutual coupling, the circuit model is improved repeatedly till the ultimate one with much simplified connection is put forward(Fig.12). S2-1 of DM modeling is shown in Fig.13,indicating excellent filtering performance.

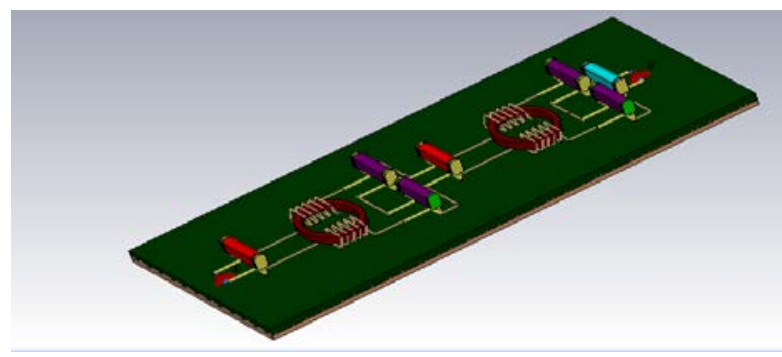

Fig.12 circuit model for DM mode modeling

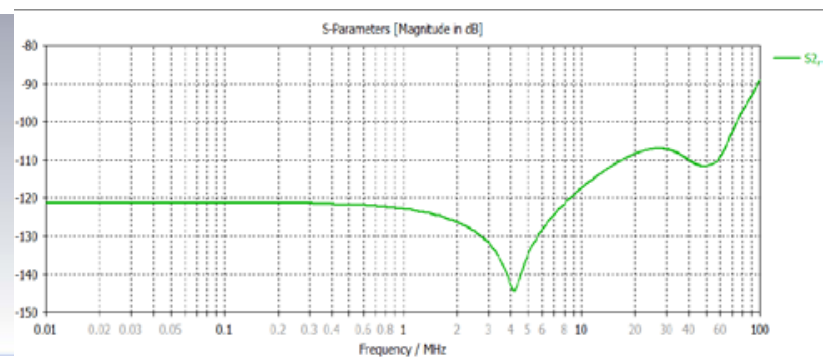

Fig.13 S2-1 of DM modeling

CM mode modeling \& analysis.

For CM interference, two ports of the circuit are connected together(Fig.14). S2-1 of CM modeling is shown in Fig.15,indicating excellent filtering performance. 


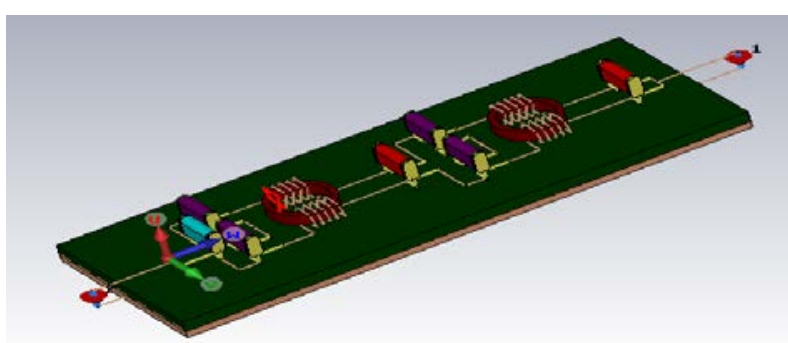

Fig.14 circuit model for CM mode modeling

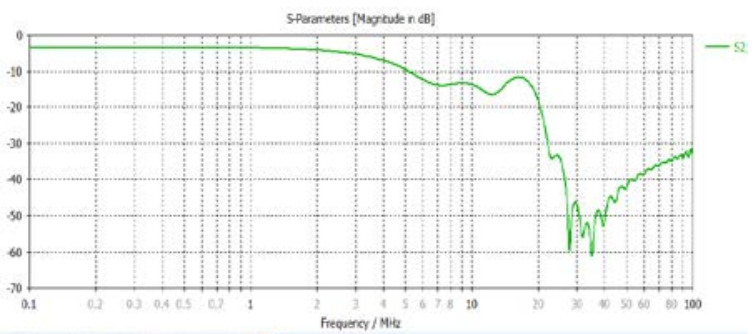

Fig.15 S2-1 of CM modeling

\section{Conclusion}

This paper focuses on the design of EMI filter in terms of component parameters using CST MWS. Capacitors and CM inductor have been modeled. The components are mounted on the PCB model in an appropriate way avoiding the impact of mutual coupling. The parameters are found to be the most suitable for filtering. The result analysis demonstrates that the filter designed in this paper functions well.

\section{References}

[1] H. Chen, Z. Qian, Z. Zeng and C. Wolf, "Modeling of Parasitic Inductive Couplings in a Pi-Shaped Common Mode EMI Filter," in IEEE Transactions on Electromagnetic Compatibility, vol. 50, no. 1, pp. 71-79, Feb. 2008.

[2] T. De Oliveira, J. L. Schanen, J. M. Guichon and L. Gerbaud, "Automatic layout optimization of an EMC filter," 2010 IEEE Energy Conversion Congress and Exposition, Atlanta, GA, 2010, pp. 2679-2685.

[3] I. F. Kovačević, T. Friedli, A. M. Müsing and J. W. Kolar, "3-D Electromagnetic Modeling of Parasitics and Mutual Coupling in EMI Filters," in IEEE Transactions on Power Electronics, vol. 29, no. 1, pp. 135-149, Jan. 2014.

[4] R. Wang, H. Fortin Blanchette, M. Mu, D. Boroyevich and P. Mattavelli, "Influence of high-frequency near-field coupling between magnetic components on EMI filter design," 2013 Twenty-Eighth Annual IEEE Applied Power Electronics Conference and Exposition (APEC), Long Beach, CA, USA, 2013, pp. 1500-1507.

[5] G. Asmanis, D. Stepins, L. Ribickis and A. Asmanis, "Modeling of mutual coupling between inductors," 2015 IEEE Symposium on Electromagnetic Compatibility and Signal Integrity, Santa Clara, CA, 2015, pp. 294-299.

[6] G. Asmanis, L. Ribickis, D. Stepins and A. Asmanis, "Differential mode П-type EMI filter modeling using CST MWS," 2015 56th International Scientific Conference on Power and Electrical Engineering of Riga Technical University (RTUCON), Riga, 2015, pp. 1-5.

[7] G. Asmanis, D. Stepins, A. Asmanis and L. Ribickis, "Capacitors mutual inductance modeling and reduction," 2014 International Symposium on Electromagnetic Compatibility, Gothenburg, 2014, pp. 1176-1181.

[8] A. Asmanis, G. Asmanis, D. Stepins and L. Ribickis, "High-frequency modelling of EMI filters considering parasitic mutual couplings," 2016 ESA Workshop on Aerospace EMC (Aerospace EMC), Valencia, 2016, pp. 1-6.

[9] A. Asmanis, G. Asmanis, D. Stepins and L. Ribickis, "Modeling of EMI filters with shields placed between the filter components," 2016 International Symposium on Electromagnetic Compatibility - EMC EUROPE, Wroclaw, 2016, pp. 776-779. 